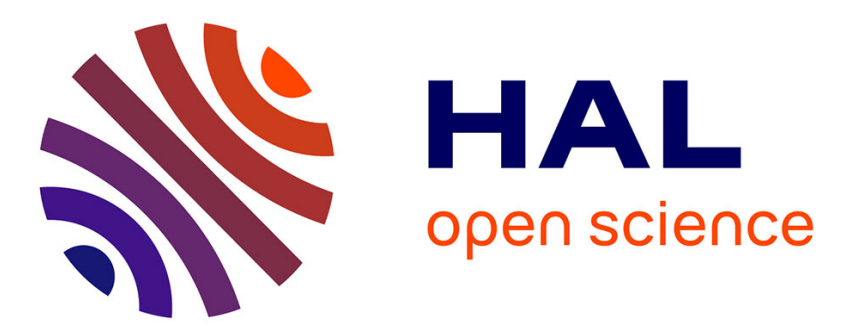

\title{
MATERIAL CHARACTERIZATION OF DUPLEX STAINLESS STEEL BY SUPERPLASTIC FREE BULGING TEST
}

\author{
J.-H. Yoon, Y.-M. Yi, H.-S. Lee
}

\section{- To cite this version:}

J.-H. Yoon, Y.-M. Yi, H.-S. Lee. MATERIAL CHARACTERIZATION OF DUPLEX STAINLESS STEEL BY SUPERPLASTIC FREE BULGING TEST. EuroSPF 2008, Sep 2008, Carcassonne, France. hal-00339332

\section{HAL Id: hal-00339332 \\ https://hal.science/hal-00339332}

Submitted on 17 Nov 2008

HAL is a multi-disciplinary open access archive for the deposit and dissemination of scientific research documents, whether they are published or not. The documents may come from teaching and research institutions in France or abroad, or from public or private research centers.
L'archive ouverte pluridisciplinaire HAL, est destinée au dépôt et à la diffusion de documents scientifiques de niveau recherche, publiés ou non, émanant des établissements d'enseignement et de recherche français ou étrangers, des laboratoires publics ou privés. 


\title{
MATERIAL CHARACTERIZATION OF DUPLEX STAINLESS STEEL BY SUPERPLASTIC FREE BULGING TEST
}

\author{
Jong-Hoon YOON ${ }^{1}$, Yeong-Moo YI ${ }^{1}$, Ho-Sung LEE ${ }^{1}$ \\ ${ }^{1}$ KOREA AEROSPACE RESEARCH INSTITUTE - 45 Eoeun-dong Yuseong, Daejeon 305-333 South Korea \\ yjh@kari.re.kr, ymy@kari.re.kr, hslee@kari.re.kr
}

\begin{abstract}
Macroscopic superplastic behaviour of metallic or non metallic materials is usually represented by the strain rate sensitivity, and it can be determined by tensile tests at elevated temperature. However, a uniaixal stress state occurs in the test whilst a multiaixal stress state is induced in actual superplastic forming processes. The difference of the stress state might affect the reliability of the strain rate sensitivity obtained from the tension test. In the current study, the material characterization of duplex stainless steel, UNS S31803, has been carried out to determine the strain rate sensitivity throughout superplastic free bulging test under constant pressure. The measured height of bulged plate during the test was transformed into strain rate and stress corresponding to height at each time by theoretical considerations. The strain rate sensitivities were calculated for each pressure level. After calculating the strain rate sensitivity and strength coefficient for each test case, the flow stress equations have been employed in the finite element simulation to verify the experiments. The bulged height obtained from the simulation showed a reasonable agreement with the experimental findings. In the future, if a study on the effect of fillet radius of test tool and microstructure evolution is carried out, it is thought that the reliability of the material characterization by superplastic free bulging test can be enhanced.
\end{abstract}

Keywords :

Duplex stainless steel, Free bulging test, Strain rate sensitivity, Flow stress, Pole displacement

\section{INTRODUCTION}

There are three representative test methods such like tensile test, cone cup test, and free bulging test for the evaluation of superplastic characteristic represented by strain rate sensitivity. Uniaxial tensile test is carried out under the uniaxial stress state and is relatively easier than other methods. However, multiaxial stress state occurs in the real forming situation, thus the strain rate sensitivity determined from the uniaxial tensile test might be a bit different. Cone cup test was suggested in order to enhance the tensile test. The cone cup test [1,2] uses a constant test pressure, and induces a constant and multiaxial stress state in the sheet. Therefore the test condition is similar to the real forming condition. However, it is difficult to exclude the friction effect which exists between the tool and workpeice and the friction condition might affect the material characterization. Free bulging test $[3,4,5]$ was also suggested to enhance the tensile test, and is similar to the cone cup test. But the test pressure changes continuously during the test in order that constant strain rate conditions can be obtained. In this case, it is difficult to control the pressure to ensure a constant strain rate.

In the current study, material characterization of superplastic duplex stainless steel which is UNS S31803 has been carried out using the free bulging test. The constant pressure rather than variable pressure was applied to the plate, and the height of the free bulged plate was measured according to time. The measured data was transformed into strain rate and stress based on membrane theory. Finally, the strain rate sensitivity and strength coefficient have been calculated from the log-scaled plot of stress $v s$. strain rate. To verify the obtained flow stress equations, a finite element simulation of the free bulging test using the obtained flow stress equations was also carried out and the results were compared with the experimental findings in terms of thickness distribution and displacement. 


\section{THEORETICAL CONSIDERATION}

The current study is based on the membrane theory. Fig. 1 shows the process of free bulging. In this case the periphery of the sheet should be constrained so that the radial displacement cannot occur, and inert gas like argon or nitrogen is applied to the sheet surface. Therefore the sheet is bulged into the mould cavity without friction. If the stress component in the thickness direction can be neglected in the free bulging process, each stress component can be expressed as follows;

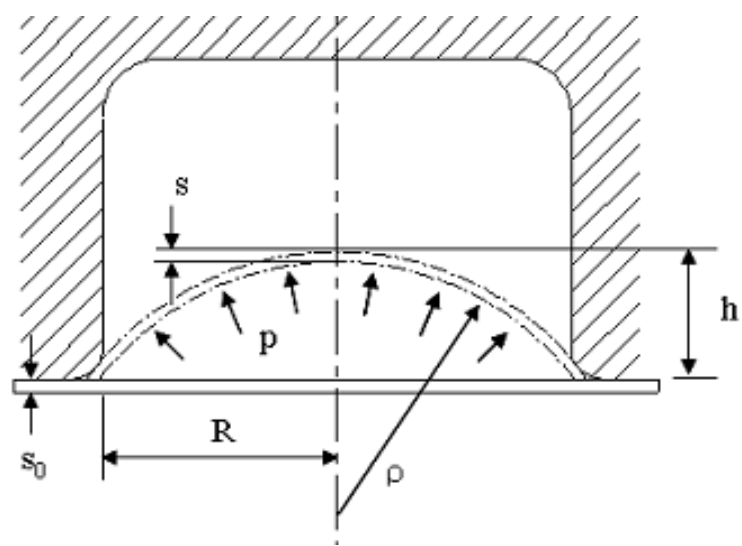

Fig. 1 Schematic representation of free bulging process.

$$
\sigma_{1}=\frac{p \rho}{2 s}=\sigma_{2}, \sigma_{3}=0
$$

Where $\sigma_{1}$ is stress in circumferential direction, $\sigma_{2}$ is stress in meridian direction, $\sigma_{3}$ is stress in thickness direction, and $\rho$ is curvature, respectively. From the von Mises yield criteria, the equivalent stress can be expressed by the following equation.

$$
\bar{\sigma}=\frac{p \rho}{2 s}=\sigma_{1}=\sigma_{2}
$$

The equivalent strain rate can be also expressed by equation (3) from the relationship between principal stress and strain suggested by Nadai.

$$
\bar{\varepsilon}=-2 \varepsilon_{1}=-2 \varepsilon_{2}=\varepsilon_{3}=\ln \frac{s}{s_{0}}
$$

$s_{0}$ is an initial thickness of the sheet and $s$ is a current thickness at time $t$.

From the geometrical relationship and the volume constancy, it is possible to obtain the thickness of the sheet at time $t$ and the equivalent strain rate;

$$
\begin{aligned}
& s=\frac{A_{0} s_{0}}{2 \pi \rho h}=\frac{R^{2} s_{0}}{R^{2}+h^{2}}, \\
& \dot{\bar{\varepsilon}}=\frac{\dot{s}}{s}=\frac{-2 h \dot{h}}{R^{2}+h^{2}} .
\end{aligned}
$$


In equation (4), $A_{0}$ is an initial area of the sheet. If the flow stress of material is a function only of equivalent strain rate, $\bar{\sigma}=\Phi(\dot{\bar{\varepsilon}})$ the relationship between the equivalent stress and strain rate will have the following form;

$$
\frac{p\left(R^{2}+h^{2}\right)^{2}}{4 h R^{2} s}=\Phi\left(\frac{-2 h \dot{h}}{R^{2}+h^{2}}\right)
$$

The only unknown variable is the height of bulged sheet, $h$ in equation (6). Thus if the height change according to time is measured throughout the experiment, it is possible to obtain the strain rate and stress by using the equations mentioned above.

\section{FREE BULGING TEST}

The material used in the current study is UNS S31803, which is a duplex stainless steel, and has been supplied as a hot-rolled plate. The initial thickness of the plate is $9.0 \mathrm{~mm}$. The chemical composition of the sheet is shown in Table 1.

Table 1 Chemical composition of UNS S31803.

\begin{tabular}{|c|c|c|c|c|c|c|c|c|c|c|c|}
\hline Comp. & $\mathrm{C}$ & $\mathrm{Si}$ & $\mathrm{Mn}$ & $\mathrm{P}$ & $\mathrm{S}$ & $\mathrm{Cr}$ & $\mathrm{Ni}$ & $\mathrm{Mo}$ & $\mathrm{Cu}$ & $\mathrm{Cb}$ & $\mathrm{Fe}$ \\
\hline $\begin{array}{l}\text { Weight } \\
\text { pct., \% }\end{array}$ & 0.017 & 0.39 & 1.51 & 0.019 & 0.001 & 22.33 & 5.74 & 3.18 & 0.11 & 0.08 & Rem. \\
\hline
\end{tabular}

\subsection{EXPERIMENTAL SETUP}

The experimental setup for the free bulging test is shown in Fig. 2. The diameter of the mould cavity is $106.0 \mathrm{~mm}$ and the fillet radius of inlet is $5.0 \mathrm{~mm}$. The diameter of the lower plate and the upper sheet is $170.0 \mathrm{~mm}$. The lower plate with $9.0 \mathrm{~mm}$ in thickness is the blank and an upper sheet with $2.0 \mathrm{~mm}$ in thickness was welded to the lower plate along the periphery in order to ensure air tightness. Gas pressure is supplied through the supply pipe welded to the upper sheet, and is applied to the surface of the plate and sheet. The displacement change according to time was measured during the bulging test.

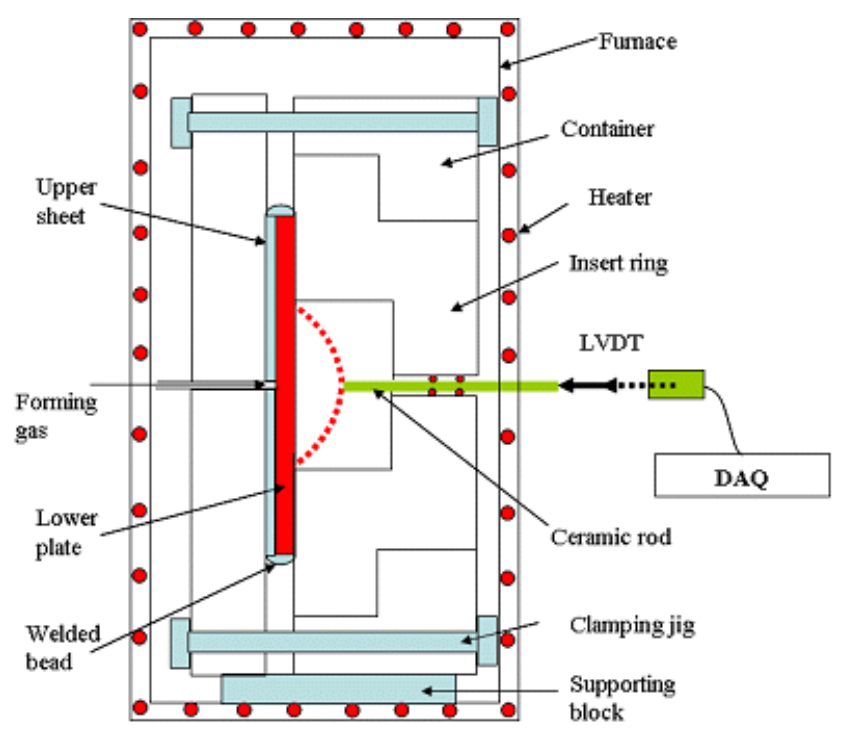

Fig. 2 Experimental setup for free bulging test. 


\subsection{TEST CONDITION}

The free bulging test was carried out under a constant temperature, $T=980{ }^{\circ} \mathrm{C}$. The test temperature was determined from several trials and preliminary tests. The test pressure was considered for two cases of 3.5 MPa and 5.5 MPa. The supplied gas pressure increases up to the target pressure within $15 \mathrm{sec}$ and is kept to be constant for $1800 \mathrm{sec}$. The displacement of the pole of bulged plate was measured according to time and was fitted to a function of time for the derivation with respect to time.

\section{DETERMINATION OF STRAIN RATE SENSITIVITY AND STRENGTH COEFFICIENT}

Fig. 3 shows the measured displacements of the pole. These height changes were expressed as an analytical function of time. Thus it is possible to obtain the rate of height change as follows;

$$
\begin{array}{ll}
h=-2.33+3.235 t^{0.286}, & \dot{h}=3.235 \times 0.286 t^{-0.714} \text { for } 3.5 \mathrm{MPa}, \\
h=3.43+1.394 t^{0.428}, & \dot{h}=1.394 \times 0.428 t^{-572} \quad \text { for } 5.5 \mathrm{MPa} .
\end{array}
$$

Thus it is possible to calculate strain rate and stress for each test by substituting equations (7) and (8) into equations (5) and (6). If the equivalent stress is only a function of the equivalent strain rate as shown in equation (9), $K$ and $m$ can be calculated from the log scaled plot of stress $v s$. strain rate.

$$
\bar{\sigma}=K \dot{\bar{\varepsilon}}^{m}
$$

where $K$ is strength coefficient and $m$ is strain rate sensitivity.

Fig. 4 shows the log scaled plot of the calculated stress and strain rate, where the data points were taken from the range between about $40 \mathrm{sec}$ and $1000 \mathrm{sec}$ in order to exclude the initial instability during the pressure rising time and the thinning effect induced in the latter part of the experiment. The obtained strength coefficient and strain rate sensitivity have been summarized in Table 2.

\section{VERIFICATION OF OBTAINED FLOW STRESS EQUATIONS}

The obtained flow stress equations have been examined through finite element analysis of the free bulging tests. The material constants were employed in the simulation, and the results were compared with experimental findings in terms of the displacement and the final thickness distribution. MSC MARC was used for the simulation, which assumed rigid viscoplastic material behaviour.

\subsection{Finite ELEMENT MODEL}

The finite element model and tool geometry are shown in Fig. 5. The symmetric condition was applied on the nodes existing on the centreline, and a pressure boundary condition was imposed on the left boundary edges. The element type used in the simulation is axisymmetric 4 node quadrilateral linear element with full integration points.

\subsection{Simulation CASES}


In order to determine the optimal material constant that can depict well the blank behaviour for both tests, the simulation has been carried out for 6 combinations as shown in Table 3 .

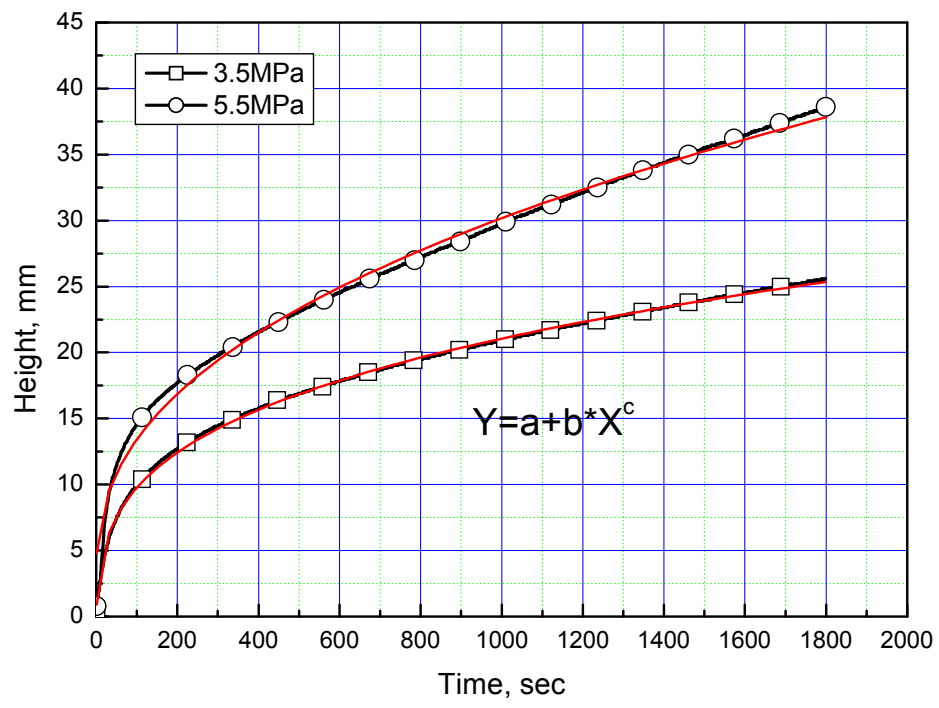

Fig. 3 Measured displacement and fitted results.

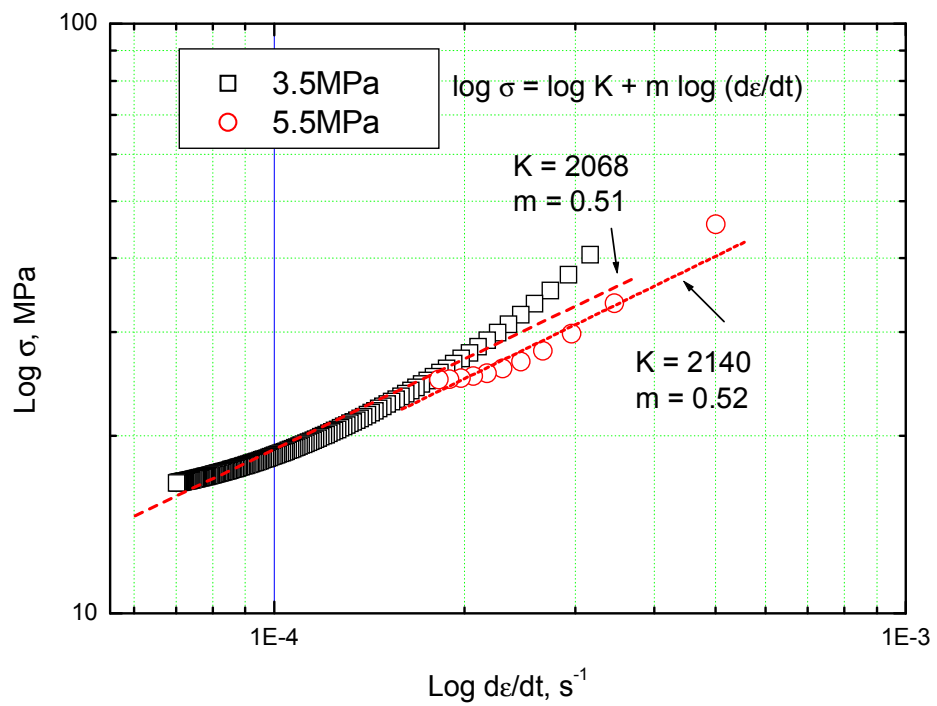

Fig. 4 Log plot of stress $v s$. strain rate.

Table 2 Calculated material constants.

\begin{tabular}{|c|c|c|c|}
\hline Pressure, $p, \mathrm{MPa}$ & $m$ & $K, \mathrm{MPa}$ & $\log K, \mathrm{MPa}$ \\
\hline 3.5 & 0.510 & 2068 & 3.3157 \\
\hline 5.5 & 0.522 & 2140 & 3.3304 \\
\hline Average & 0.516 & 2104 & 3.3231 \\
\hline
\end{tabular}




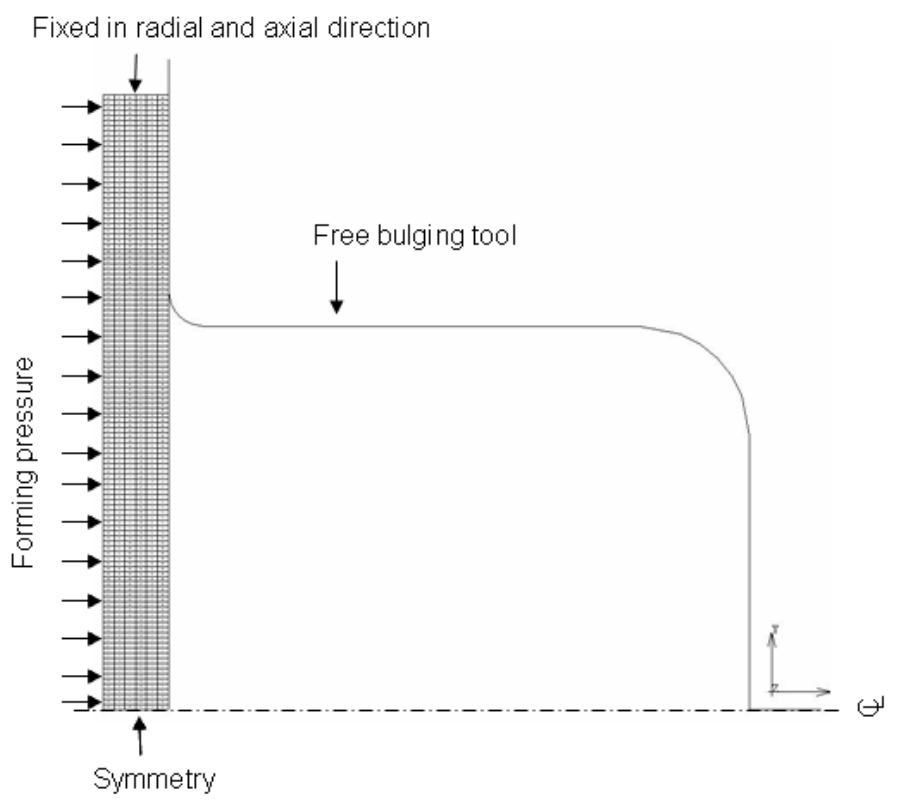

Fig. 5 Initial finite element model and boundary conditions.

Table 3 Simulation cases.

\begin{tabular}{|c|c|c|c|c|}
\hline Case & Pressure, $p, \mathrm{MPa}$ & $m$ & $K, \mathrm{MPa}$ & Comment \\
\hline \multirow{2nnyy}{*}{1} & \multirow{3}{*}{3.5} & 0.510 & 2068 & \\
\cline { 1 - 3 } 2 & & 0.522 & 2140 & \\
\cline { 1 - 3 } 3 & & 0.516 & 2104 & Average \\
\cline { 1 - 3 } 4 & \multirow{3}{*}{5.5} & 0.510 & 2068 & \\
\cline { 1 - 3 } 5 & & 0.522 & 2140 & \\
\cline { 1 - 3 } 6 & & 0.516 & 2104 & Average \\
\hline
\end{tabular}

\subsection{RESULT AND DISCUSSION}

Fig. 6 shows the comparison of the displacements obtained from the simulation and experiment for the cases of $p=3.5 \mathrm{MPa}$ (Fig. 6(a)) and 5.5 MPa (Fig. 6(b)), respectively. From this comparison, it can be recognized that Case 6 showed a good agreement between the simulation and the experiment for 5.5 MPa test pressure while Case 2 showed comparatively less deviation at the final time for 3.5MPa. However, the deviation of Case 3 within about $1200 \mathrm{sec}$ is less than Case 2 and shows a reasonable agreement with the experiment compared to Case 3. These phenomena can be explained from two facts. First, since the data between $t=$ $40 \mathrm{sec}$ and $\mathrm{t}=1000 \mathrm{sec}$ was taken for the calculation of $K$ and $m$, the latter part of the displacement obtained from the simulation might be inaccurate. Secondly, the deformation mode around the fillet radius of the forming tool differs from the experimental measurement. It might affect the displacement at the pole of the bulged plate. Therefore, if a study on the optimal fillet radius is carried out, the degree of the precision of the experiment will increase. From the above comparison and discussion, it can be concluded that the averaged values, $m=$ 0.516 and $K=2104 \mathrm{MPa}$, would be the appropriate material constant for the prediction of superplastic behaviour of UNS S31803. 


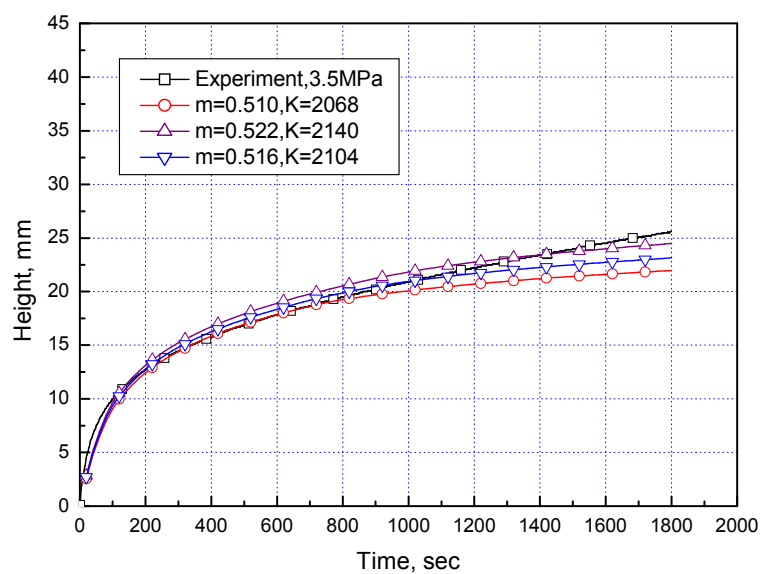

(a) $p=3.5 \mathrm{MPa}$

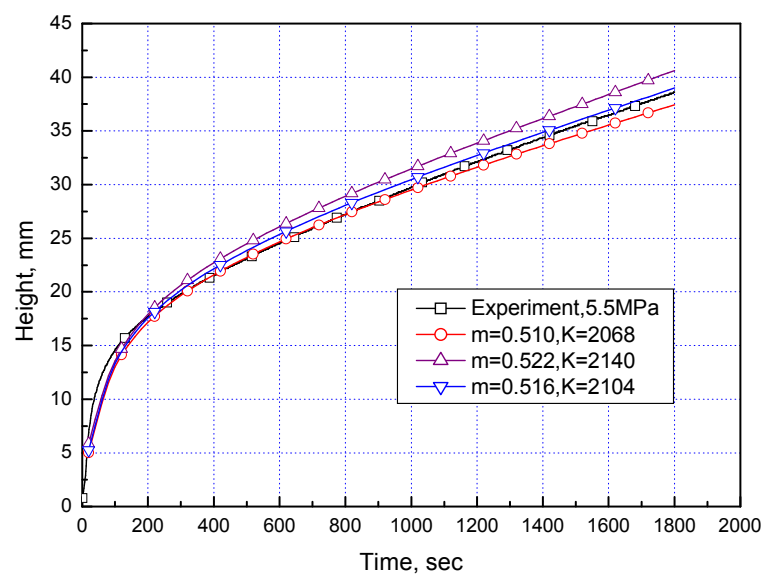

(b) $p=5.5 \mathrm{MPa}$

Fig. 6 Comparison of displacement; (a) $p=3.5 \mathrm{MPa}$ and (b) $p=5.5 \mathrm{MPa}$.

Fig. 7 shows the comparison of the final deformed shape of Case 3 and Case 6 with the experiment, in which the dashed line represents the measured value. As mentioned in the above, a little deviation was observed around the fillet radius for both cases.

The comparison of thickness distribution is shown in Fig. 8. In the case of Fig. 8(a), the maximum difference of about $0.16 \mathrm{~mm}$ exists on the symmetric axis and the difference decreases with increase in radial position. Fig. 8(b) shows the opposite trend. However, since the percentage error is less than $6 \%$ for the displacement and 3\% for thickness distribution, the flow stress equation with averaged material constant seems to be reasonable.

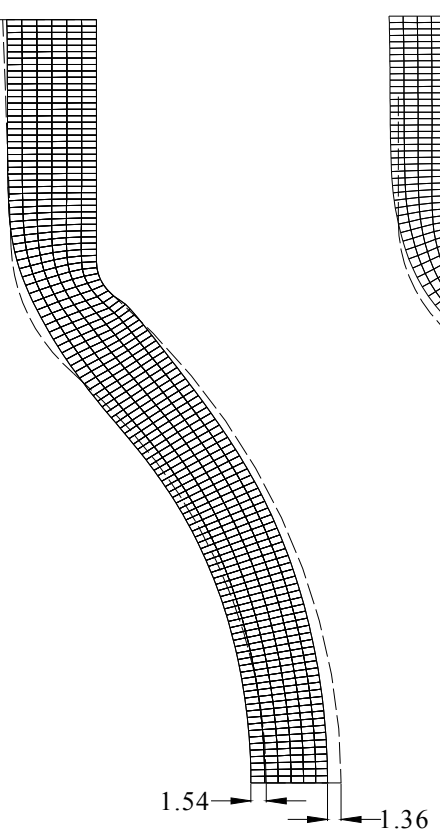

(a) $p=3.5 \mathrm{MPa}$

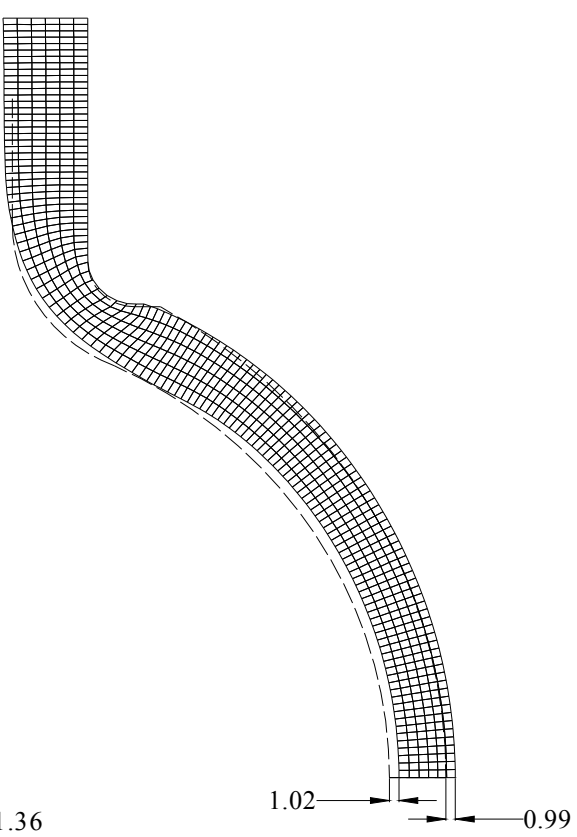

(b) $p=5.5 \mathrm{MPa}$

Fig. 7 Deformed shape comparison between the FE analysis results and the experimental measurements; (a) $p=3.5 \mathrm{MPa}$ and (b) $p=5.5 \mathrm{MPa}$. 


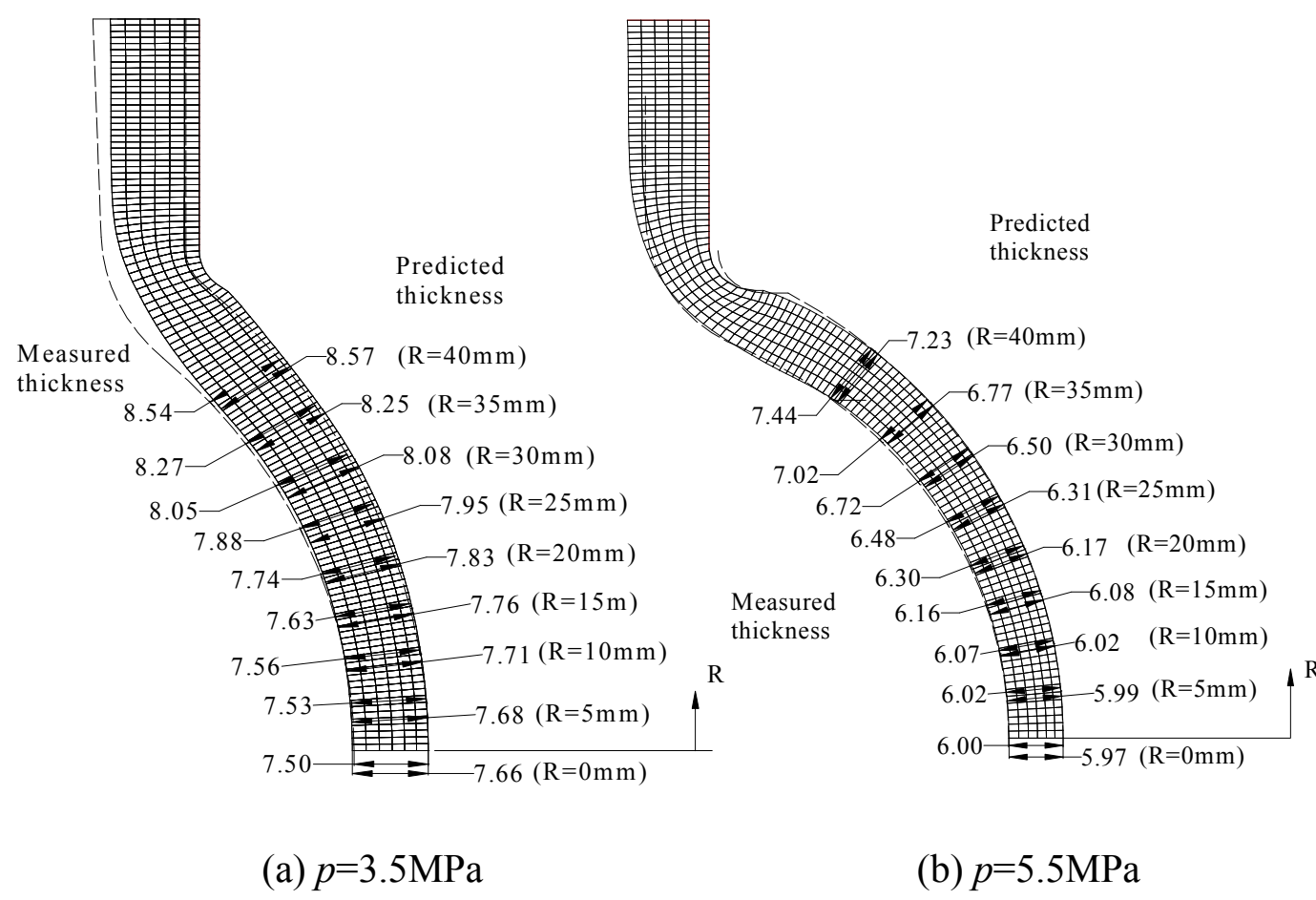

Fig. 8 Thickness distribution comparison between the FE analysis results and the experimental measurements; (a) $p=3.5 \mathrm{MPa}$ and (b) $p=5.5 \mathrm{MPa}$.

\section{Conclusion}

From the free bulging test of UNS S31803, the following conclusion can be obtained.

(1) Free bulging test using constant pressure can also be an alternative superplastic material characterization method.

(2) The flow stress equation for the given duplex stainless steel has been determined to be

$$
\bar{\sigma}=2104 \dot{\bar{\varepsilon}}^{0.516} \mathrm{MPa}
$$

(3) The error was less than $6 \%$ and 3\% in terms of the displacement and thickness distribution, respectively; thus the determined flow stress equation seems reasonable.

(4) In order to increase the degree of precision for the free bulging test, a study on the effect of fillet radius of test tool should be carried out in the future.

(5) A study on the determination of optimal strain rate should be also carried out to obtain an optimal superplastic forming condition.

Finally, if the effect of the microstructure evolution during the free bulging is introduced into the flow stress equation, more reliable material characterization can be carried out.

\section{REFERENCES}

[1] R.J. Lederich, S.M.L. Sastry, M. Hayase, and T.L. Mackay, Superplastic Formability Testing. Journal of Metals, August 1982, p. 16-20. 
[2] A.K. Ghosh and C.H. Hamilton, On Constant Membrane Stress Test for Superplastic Metals. Metallurgical Transactions A, 1980. 11A, p. 1915-1918.

[3] Abhijit Dutta and Amiya K. Mukherjee, Superplastic forming: an analytical approach. Material Science and Engineering, 1992. A157, p. 9-13.

[4] G.C. Cornfield and R.H. Johnson, The Forming of Superplastic Sheet Metal. International Journal of Mechanical Science, 1970. 12, p. 479-490.

[5] F. Jovane, An Approxiamte Analysis of the Superplastic Forming of a Thin Circular Diaphragm: Thoery and Experiments. International Journal of Mechanical Science, 1968. 10, p. 403-427. 